\title{
Nanoparçacık Takviyeli Epoksi Nanokompozitlerin Eğilme Davranışları
}

\author{
Kazım Tolga Çınar ${ }^{1}$, Mürsel Ekrem²* \\ ${ }^{1}$ Necmettin Erbakan Üniversitesi, Mühendislik Fakültesi, Makine Mühendisliği Bölümü, Konya, Türkiye, (ORCID: 0000-0002-8499-5361), \\ kazimtolgacinar@gamil.com \\ $2^{2 *}$ Necmettin Erbakan Üniversitesi, Mühendislik Fakültesi, Makine Mühendisliği Bölümü, Konya, Türkiye (ORCID: 0000-0001-5324-7929), mekrem@erbakan.edu.tr
}

(1st International Conference on Applied Engineering and Natural Sciences ICAENS 2021, November 1-3, 2021)

(DOI: 10.31590/ejosat.1015227)

ATIF/REFERENCE: Çınar, K. T. \& Ekrem, M. (2021). Nanoparçacık Takviyeli Epoksi Nanokompozitlerin Eğilme Davranışları. European Journal of Science and Technology, (28), 1415-1418.

$\ddot{O} z$

Kompozit malzemeler iki veya daha fazla farklı malzeme grubunun makro boyutlarda bir araya gelmesiyle oluşan yeni nesil mühendislik malzemeleri olarak tanımlanmaktadır. Bu iki fazın birleşmesi sonucu malzeme özellikleri, matris ve takviye fazının güçlü özelliklerinin kombinasyonu şeklinde ortaya çıkmaktadır. Matris fazına eklenen takviye fazı çoğu zaman matrisin özelliklerini geliştirirken, bazı durumlarda mekanik özelliklerde düşüşe sebep olabilmektedir. Böyle durumlarda takviye fazının boyutunun nano seviyeye düşürülmesi gerekmektedir. $\mathrm{Bu}$ şekilde matris fazına nano boyutta yapılan ilaveler ile yeni nesil nanokompozit malzemeler geliştirilmiştir. Bu çalışmada, nanoparçacık takviyeli epoksi nanokompozitlerin eğilme dayanımı incelenmiş̧tir. Ağırlıkça \%0,25 Çok Cidarlı Karbon Nanotüplerle (ÇCKNT) ve ağırlıkça \%0.25, 0.5, $0.75 \mathrm{SiO}_{2}$ nanoparçacıklarla güçlendirilmiş takviyeli epoksi kompozit malzemelerin eğilme testleri, ASTM D790 standartlarına göre incelenmiştir. Epoksi reçinesi olarak Hexion MGS L160 kullanılmıştır. hibrid nanoparçacıklarla takviyeli epoksi nanokompozitlerin eğilme dayanımları epoksi reçineyle elastiklik modülü, eğilme dayanımları, birim şekil değişimleri karşılaştırılmıştır. Eğilme testi sonuçlarına göre en uygun ilave oranının $\% 0,25 \mathrm{SiO}_{2}$ ve $\% 0,5$ ÇCKNT olduğu görülmüş ve saf epoksiye göre \%80,38 artışla en yüksek eğilme dayanımı 138,42 MPa olarak elde edilmiştir. Daha yüksek ilave oranlarında ise eğilme dayanımı değerleri bakımından bir düşüş olduğu gözlemlenmiștir. Takviyelendirme sayesinde epoksiye göre eğilme dayanımda artış görülürken birim şekil değiştirmelerde azalma görülmüştür. Maksimum yükleme miktarında $\% 71,47$ oranında artış meydana gelmiştir.

Anahtar Kelimeler: Nano Silisyum oksit, Çok Cidarlı Karbon Nanotüp, Epoksi, Nanokompozit, Eğilme testi.

\section{Flexural Behaviors of Nanoparticle Reinforced Epoxy Nanocomposites}

\begin{abstract}
Composite materials are defined as new generation engineering materials that are formed by the combination of two or more different material groups in macro dimensions. As a result of the combination of these two phases, the material properties emerge as a combination of the strong properties of the matrix and reinforcement phase. While the reinforcement phase added to the matrix phase often improves the properties of the matrix, it may cause a decrease in the mechanical properties in some cases. In such cases, the size of the reinforcement phase should be reduced to the nano level. In this way, new generation nanocomposite materials have been developed by adding nanoscale to the matrix phase. In this study, the flexural strength of nanoparticle reinforced epoxy nanocomposites was investigated. Bending tests of reinforced epoxy composite materials reinforced with $0.25 \%$ by weight Carbon Nanotubes (CNT) and $0.25 \%, 0.5,0.75 \%$ by weight $\mathrm{SiO}_{2}$ nanoparticles were investigated according to ASTM D790 standards. Hexion MGS L160 was used as epoxy resin. The flexural strength of epoxy nanocomposites reinforced with hybrid nanoparticles, the modulus of elasticity, flexural strength and unit shape changes of epoxy resin were compared. According to the flexural test results, it was seen that the most suitable addition ratio was $0.25 \% \mathrm{SiO}_{2}$ and $0.5 \% \mathrm{CNT}$, and the highest flexural strength was obtained as $138.42 \mathrm{MPa}$, with an increase of $80.88 \%$ compared to pure epoxy. It has been observed that there is a decrease in flexural strength values at higher addition rates. Thanks to the reinforcement, an increase in flexural strength was observed compared to epoxy, while a decrease in unit strains was observed. There was an increase of $71.47 \%$ in the maximum loading amount.
\end{abstract}

Keywords: Nano Silicon oxide, Multi-Wall Carbon Nanotube, Epoxy, Nanocomposite, Flexural test. 


\section{Giriş}

Mükemmel fiziksel ve kimyasal bağlara sahip epoksi reçineler günümüzde uygulanan mühendislik uygulamaları için gerekli kabul edilirler. Günümüzde sanayide epoksi bazlı kompozitlerde matris malzemesi olarak çapraz bağlı polimer ağları mekanik özellikleri, düşük yoğunlukları, 1sıl kararlılıkları, 1S1 direnci, yapışma mukavemeti, kimyasal ve elektriksel direnci yüzünden tercih edilirler (Ekrem, 2019a; Wong, Zhang, Bilotti, \& Peijs, 2017).

Bununla birlikte içerisinde yüksek çapraz bağ yoğunluğu bulunduran epoksi reçineler kırılganlığa ve sınırlamalara neden olurlar. Bu sebepten dolayı darbe dayanımları azalır. Bu durum epoksi reçinenin kullanımını sınırlar. Nanoparçacıkların epoksiye dahil edilmesine yönelik birçok sayıda araştırma, polimerlerin mekanik, fiziksel ve kimyasal özelliklerinin geliştirilebilmesi için kolay ve ekonomik bir yöntem olduğunu göstermiştir (Afrouzian, Movahhedi Aleni, Liaghat, \& Ahmadi, 2017; Ahmadi, 2019; Ekrem, 2019b).

Nanokompozitler, aralarında farklı arayüzler veya sınırlar bulunan en az bir boyutu nano düzeyde bir matrise gömülü bir takviyeden oluşan malzemeler olarak tanımlanabilir (Yadav \& Cho, 2013; Jiang et al., 2018). Matrisin işlevselliği, takviyeyi istenen bir geometride tutmaktır ve takviyelerin ise, uygulama amacına göre nanokompozit malzemelerin özelliklerini iyileştirmeye yardımcı olur (Vaithylingam, Ansari, \& Shanks, 2017; Erkendirci \& Avc1, 2020). Polimerler genellikle matris olarak sürekli faz olarak hareket ederken nanoparçacıklar ise süreksiz faz olarak kompozit malzemenin hasar mekanizmalarını iyileştirerek hem mukavemetini hem de tokluğunu geliştirir (Atiqah, Mastura, Ali, Jawaid, \& Sapuan, 2017; Farooq et al., 2020; Ekrem, 2019c). Yüksek mukavemetli bir nanoparçacık/epoksi nanokompozit hazırlanması için hem polimer matrisinde nanoparçacıkların dağılımına hem de nanoparçacık ile matris arasındaki arayüzey etkileşimine bağlıdır. Çözelti karıştırma, eriyik harmanlama ve in situ polimerizasyon gibi nanoparçacıkları polimer matrislerdeki dağılımını iyileştirmek için geliştirilmiş çeşitli yöntemlerdir (Navidfar, Sancak, Yildirim, \& Trabzon, 2018; Hong et al., 2015).

$\mathrm{Bu}$ çalışmada, ağırlıkça farklı oranlarda nanoSiO2 ile ağırlıkça \% 0.25 Çok Cidarlı Karbon Nanotüp (ÇCKNT) takviyeli epoksi kompozit malzemelerin eğilme testi altındaki mekanik özellikleri iyileştirilmesi incelenmiştir. Hibrid nanopaçacık takviyeli epoksi kompozitler, ASTM D790 standardına göre üç nokta eğilme testi altında eğilme gerilmeleri, toklukları, birim şekil değişimleri ve maksimum yükleri referans malzeme karşılaştırılmıştır.

\section{Materyal ve Metot}

\subsection{Materyal}

Çalışmamızda matris malzemesi olarak Epoksi (MGS LR160 MomentiveHexion) reçinesi ve nano takviye olarak $\mathrm{SiO} 2$ nanopartikülleri (15-50 nm Grafen Chemical Industries Co.) ve NANOCYL (5-50nm) firması tarafindan üretilen MWCNT'ler kullanılmıştır. Kürleştirici ise yine Hexion markasının MGS H160 kodlu ürünüdür (ağırlıkça 100:40). Jelleşme zamanı oda sıcaklığında firmanın belirttiği oranlarda kullanıldığında yaklaşık 2 ile 3 saattir.

\subsection{Kalıpların Hazırlanması}

Eğilme testleri için ASTM D790 standardına uygun olarak önceden hazırlanan çelik kalıplara, epoksi reçinenin yapışmaması için vaks yardımıyla ince bir tabaka oluşturacak şekilde sürülmüştür. Montajı yapılan bu kalıplara hazırlanan nanokompozit malzemelerin dökülme işlemi gerçekleştirilmiştir. Test sonuçlarının güvenilirliğini sağlamak için aynı özellikteki numuneden 4 adet üretilmiştir. Şekil 1'de eğilme kalıplarının işlem basamakları görülmektedir.

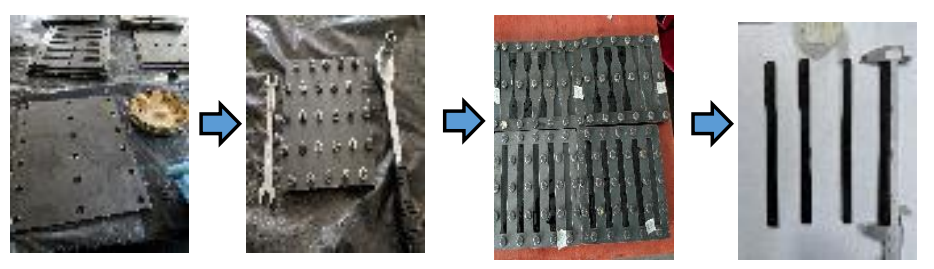

Şekil 1. Eğilme Deneyleri için kalıpların hazırlanması

\subsection{Nanoparçacık Takviyeli Epoksi Kompozitlerin Hazırlanması}

Şekil 2'de ağırlıkça \% 0.25 oranında MWCNT ve farklı ağırlıklarda $\mathrm{SiO}_{2}$ takviyeli epoksi nanokompozitlerin hazırlanması akış şeması olarak gösterilmiştir. Epoksi hassas terazide beherin darası önceden hesaplanmış şekilde beher içinde tartılmıștır. Sırasıyla epoksinin ağırlıkça \%0.25 MWCNT ve $\% 0,25 \% 0,5 \% 0,75$ oranlarında $\mathrm{SiO}_{2}$ önceden hazırlanmış alüminyum folyo üzerinde hassas terazide tartıldıktan sonra epoksi reçineye karıştırılmıştır. Epoksi reçinenin viskozitesini arttırmak için aseton ilave edilmiştir. Daha sonra nanopartikül ilaveli epoksi reçine problu homojenizatörle 5'er dk aralıklarla toplamda $15 \mathrm{dk}$ karıştırılmıştır. Çok ısınan karışım beher içerisinde aralıklarla buz banyosu yaptırılarak 3 saat boyunca oda sıcaklığında soğumaya bırakılmıştır. Beklendikten sonra karışımın içerisine epoksinin ağırlığınca 100:40 oranında kürleştirici eklenmiştir. Kürleştirici ilavesinden sonra hava kabarcıklarını gidermek amacıyla elle mekanik olarak en az $10 \mathrm{dk}$ karıştırılmıştır. Daha sonra yine hava kabarcıklarını gidermek amacıyla vakum cihazında yaklaşık olarak $20 \mathrm{dk}$ boyunca 0.25 bar altında vakumlanmıştır.

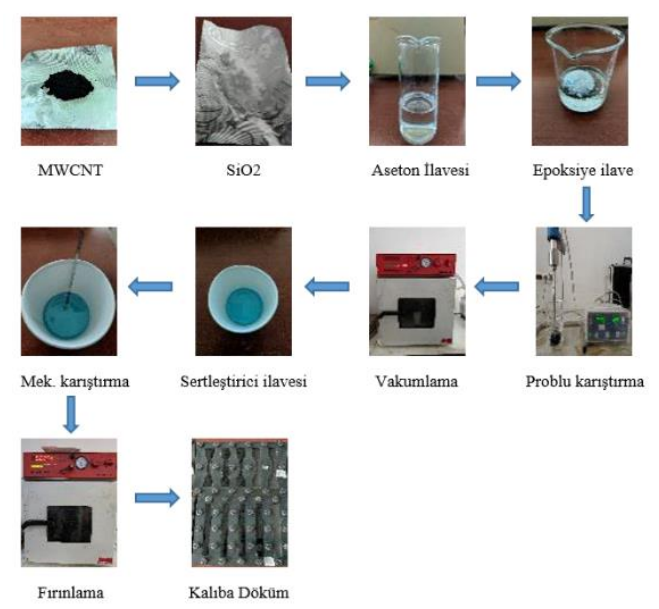

Şekil 1. Nanoparçacık takviyeli epoksi nanokompozitlerin hazırlanması şematik gösterim 
Vakum işlemi gören karışım eğilme testleri için 4x13×128 boyutunda önceden hazırlanmış çelik kalıplara dökülmüştür. Kalıplara dökülen karışımlar oda sıcaklığında 24 saat boyunca külemeye bırakılmıştır. Son kürleme işlemi için $80^{\circ} \mathrm{C}$ 'de 15 saat firında gerçekleştirilmiştir.

\subsection{Karakterizasyon}

ASTM D790'a göre 4x13×128 mm ölçülerinde dikdörtgen kesitli bir parça halinde olan numuneler üretilmiştir. Testler $2 \mathrm{~mm} / \mathrm{dk}$ hızında uzama kontrollü yapılmıştır. Shimadzu AGS-X Üniversal Çekme Test Cihazı kullanılarak $1 \mathrm{kN}$ yük hücresinde deneyler gerçekleştirilmiştir (Şekil 3.). Bütün testler oda sıcaklığında yapılmıştır.

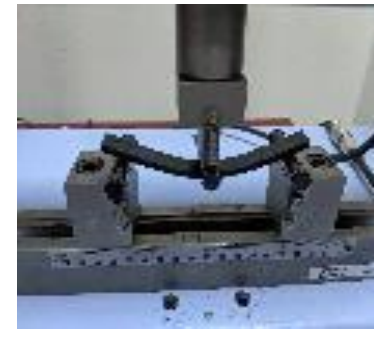

Şekil 3. 3 nokta eğilme deneyi

Tablo 1. MWCNT ve $\mathrm{SiO}_{2}$ takviyeli epoksi nanokompozit malzemelerin mekanik özellikleri

\begin{tabular}{l|c|c|c|c}
\hline Numuneler & Maks yük (N) & $\begin{array}{c}\text { Maks \% uzanma } \\
\mathbf{( m m )}\end{array}$ & $\begin{array}{c}\text { Maks eğilme gerilme } \\
\mathbf{( M P a )}\end{array}$ & $\begin{array}{c}\text { Birim şekil değişimi } \\
(\mathbf{m m} / \mathbf{m m})\end{array}$ \\
\hline Epoksi & 103.9 & 29.40 & 76.73 & 0.067 \\
\hline $0.25 \mathrm{CNT}$ & 118.2 & 23.65 & 88.11 & 0.054 \\
\hline $0.25 \mathrm{CNT}+0.25 \mathrm{SIO}_{2}$ & 113.7 & 29.20 & 98.11 & 0.053 \\
\hline $0.25 \mathrm{CNT}+0.5 \mathrm{SIO}^{2}$ & 178.2 & 21.1 & 138.41 & 0.049 \\
\hline $0.25 C N T+0.75 \mathrm{SIO} 2$ & 111.0 & 23.94 & 85.60 & 0.053 \\
\hline
\end{tabular}

\section{Araştırma Sonuçları ve Tartışma}

\subsection{Nokta Eğilme Deneyi}

Tüm deneylerde ASTM D790 standardına göre ölçme uzunluğu/derinlik oranı sabit olarak 32:1 alınmıştır. Yük iş numunesi ortasına uygulanmış olup parça kırılıncaya kadar devam etmiştir. Ölçülen verilerin ortalaması alınmıştır. Her bir numuneye uygulanan yük $\mathrm{P}$ ve sehim $\delta$ değerleri anlık olarak kayıt edilmiş ve numunelerin eğilme dayanımları aşağıdaki denklem 1 ile hesaplanmıştır;

$$
\sigma_{\max }=\frac{3 P_{\max } L}{2 b h^{2}}
$$

Denklem 1.'de $\sigma_{\max }$ numunenin orta noktasında dış yüzeyde oluşan gerilmeyi (MPa), P uygulanan yükü $(\mathrm{N})$, L mesnetler arası açıklığı $(\mathrm{mm}), \mathrm{b}$ numunenin genişliğini $(\mathrm{mm})$ ve $\mathrm{h}$ ise numune kalınlığını (mm) göstermektedir.

Numunenin orta noktasında dış yüzeyinin şekil değişimimi ise aşağıdaki denklem ile hesaplanmıştır;

$$
\varepsilon=\frac{6 D d}{L^{2}}
$$

Denklem 2.'de dış yüzeyde oluşan en büyük şekil değiştirme miktarını $(\mathrm{mm} / \mathrm{mm}), \delta$ orta noktadaki sehimi $(\mathrm{mm})$ ve L mesnetler arası açıklığı $(\mathrm{mm})$ belirtmektedir.

Şekil 4 'te $\% 0.25$ MWCNT ve sirasıyla $\% 0.25 \% 0.5 \% 0.75$ $\mathrm{SiO} 2$ takviyeli epoksi nanokompozitlerin 3 nokta eğilme deneyinden sonraki gerilme-birim şekil değiştirme grafiği verilmiştir.

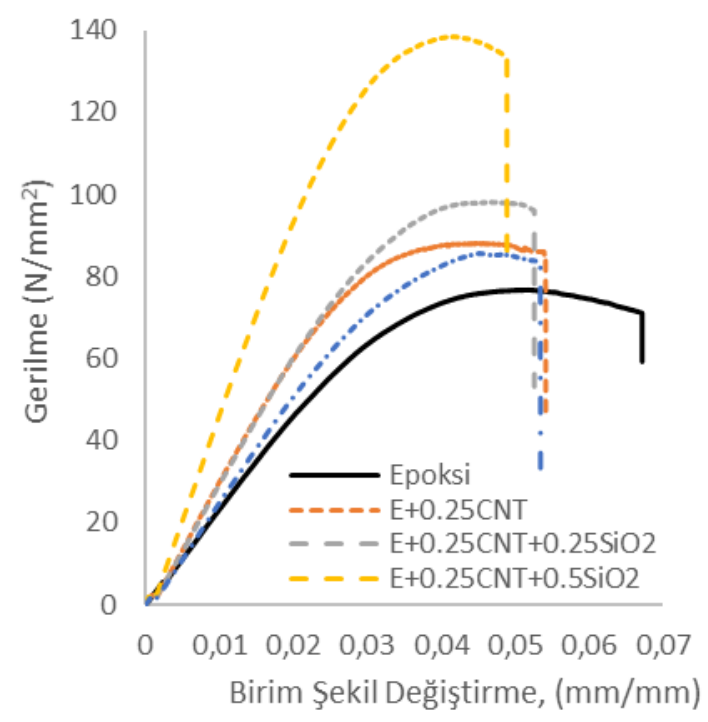

Şekil 4. Hibrid nanoparçalk takviyeli epoksi kompozit malzemelerin gerilme-birim şekil değiştirme ĕgrileri

Takviyelendirme sayesinde epoksiye göre eğilme dayanımda artış görülürken birim şekil değiştirmelerde azalma görülmüştür. Malzeme epoksiye göre daha elastik şekil değişime dönüşmüştür. Saf epokside max eğilme dayanımı 76,73 Mpa iken $0.25 \mathrm{CNT}$ ve $0.5 \mathrm{SiO}_{2}$ takviyeli epoksi matris max eğilme dayanımı 138,41 Mpa değerini görmüştür. Aradaki artış miktarı \%80,38' dir.

Saf epoksinin max yükleme, max uzama, max B.Ş.D değerleri sirasıyla $103.91 \mathrm{~N}, 29.4 \mathrm{~mm}$ ve $0.0672 \mathrm{~mm} / \mathrm{mm}$ bulunmuştur. Ağırlıkça \%0.25CNT ve $\% 0.5 \mathrm{SiO}_{2}$ takviyeli epoksi nanokompozit malzemenin max yükleme, max uzama, max B.Ş.D değerleri sırasıyla $178.18 \mathrm{~N}, 21.91 \mathrm{~mm}, 0.0489 \mathrm{~mm} / \mathrm{mm}$ olarak ölçülmüştür. Max yükleme miktarında \%71,47 oranında artış meydana gelmiştir. Değerlere bakıldığı zaman $0.25 \mathrm{CNT}$ ve $0.5 \mathrm{SiO} 2$ takviyeli epoksi nanokompozit malzemenin elastik 
kırılma gösterdiği sonucuna varılabilir. Ayrıca Tablo 1'de eğilme test sonucunda elde edilen değerler verilmiştir.

\section{Sonuç}

Epoksi yapıştırıcı, ağırlıkça \%0.25 MWCNT, \%0.25 MWCNT $+\% 0.25,0.5$ ve 0.75 nano $\mathrm{SiO}_{2}$ parçacık takviyeli hibrit nanoparçacık takviyeli epoksi nanokompozitlerin, eğilme dayanımları incelenmiştir. Eğilme testinde $0.25 \mathrm{CNT}+0.5 \mathrm{SiO}_{2}$ takviyeli epoksi nanokompozitlerde eğilme dayanımı saf epoksiye kıyaslandığında \%80.38 artış göstermiştir.

Sonuçlardan da görüldüğü üzere MWCNT ve $\mathrm{SiO}_{2}$ nanoparçacık takviyesi malzemenin dayanımı arttırmak için kullanıldığında etkili sonuçlar verdiği görülmüştür.

\section{Kaynakça}

Afrouzian, A., Movahhedi Aleni, H., Liaghat, G., \& Ahmadi, H. (2017). Effect of nano-particles on the tensile, flexural and perforation properties of the glass/epoxy composites. Journal of Reinforced Plastics and Composites, 36(12), 900-916.

Ahmadi, Z. (2019). Nanostructured epoxy adhesives: A review. Progress in Organic Coatings, 135, 449-453.

Atiqah, A., Mastura, M. T., Ali, B. A. A., Jawaid, M., \& Sapuan, S. M. (2017). A Review on Polyurethane and its Polymer Composites. Current Organic Synthesis, 14(2), 233-248. doi:10.2174/1570179413666160831124749

Ekrem, M. (2019a). The effects of carbon nanotubes added polyvinyl alcohol nanofibers on mechanical properties of carbon reinforced composite laminates. Sādhanā, 44(8), 179. doi:https://doi.org/10.1007/s12046-019-1161-6

Ekrem, M. (2019b). Hexagonal Boron Nitride Nanoplates-Nano Ag / Epoxy Composites: Production, Mechanical and Thermal Properties. El-Cezeri Journal of Science and Engineering, 6(3), 585-593.

Ekrem, M. (2019c). Shear strength of boron nitride nanoplatelets and nano Ag reinforced structural adhesives. Journal of Bor, 4(3), 128-134. doi:https://doi.org/10.30728/boron.568138

Erkendirci, Ö. F., \& Avc1, A. (2020). Quasi-static impact resistance and damage mechanisms of polymer hybrid nanocomposites. Plastics, Rubber and Composites, 49(1), 2534.

Farooq, M. U., Jan, R., Azeem, M., Umer, M. A., Akram, M. A., Khan, A. N., . . . Liaqat, U. (2020). Enhanced mechanical properties of functionalized $\mathrm{BN}$ nanosheets-polymer composites. Journal of Polymer Research, 27(10). doi:ARTN 31010.1007/s10965-020-02286-Z

Hong, S. K., Kim, D., Lee, S., Kim, B. W., Theilmann, P., \& Park, S. H. (2015). Enhanced thermal and mechanical properties of carbon nanotube composites through the use of functionalized CNT-reactive polymer linkages and three-roll milling. Composites Part a-Applied Science and Manufacturing, 77, 142-146. doi:10.1016/j.compositesa.2015.05.035

Jiang, S., Chen, Y., Duan, G., Mei, C., Greiner, A., \& Agarwal, S. (2018). Electrospun nanofiber reinforced composites: A review. Polymer Chemistry, 9(20), 2685-2720. doi:https://doi.org/10.1039/C8PY00378E

Navidfar, A., Sancak, A., Yildirim, K. B., \& Trabzon, L. (2018). A Study on Polyurethane Hybrid Nanocomposite Foams Reinforced with Multiwalled Carbon Nanotubes and Silica Nanoparticles. Polymer-Plastics Technology and
Engineering,

$57(14)$ doi:10.1080/03602559.2017.1410834

Vaithylingam, R., Ansari, M. N. M., \& Shanks, R. A. (2017). Recent Advances in Polyurethane-Based Nanocomposites: A Review. Polymer-Plastics Technology and Engineering, 56(14), 1528-1541. doi:10.1080/03602559.2017.1280683

Wong, D. W., Zhang, H., Bilotti, E., \& Peijs, T. (2017). Interlaminar toughening of woven fabric carbon/epoxy composite laminates using hybrid aramid/phenoxy interleaves. Composites Part A: Applied Science and Manufacturing, 101, 151-159.

Yadav, S. K., \& Cho, J. W. (2013). Functionalized graphene nanoplatelets for enhanced mechanical and thermal properties of polyurethane nanocomposites. Applied Surface Science, 266, 360-367. doi:10.1016/j.apsusc.2012.12.028 